\title{
On Pollution Permit Banking and Market Power
}

\author{
Matti Liski and Juan-Pablo Montero*
}

February 8, 2005

\begin{abstract}
We consider a pollution permits market in which there are a large polluting firm plays and a fringe of competitive firms. To smooth compliance towards the longrun emissions goal, firms are initially allocated a stock (i.e., bank) of permits to be gradually consumed. We first show how the large firm can credibly manipulate the spot market in subgame-perfect equilibrium. Motivated by features observed in the market for sulfur dioxide emissions of the US Acid Rain Program, we then show that the introduction of stock transactions has no effects on market power, but that forward trading and incomplete observability of stock holdings do have pro-competitive effects.
\end{abstract}

JEL classification: L51; Q28.

\section{Introduction}

Pollution permit markets are usually about trading across space in the same period, but they can also entail trades over time. Typically, permit market designs allow intertemporal trading in the form of banking which means that unused permits in one period can be saved and used in later periods. Over the past decade, this latter dimension of pollution

${ }^{*}$ Liski (liski@hkkk.fi) is at the Economics Department of the Helsinki School of Economics and Montero (jmontero@faceapuc.cl) is at the Economics Department of the Catholic University of Chile (PUC). Both authors are also Research Associates at the MIT Center for Energy and Environmental Policy Research. Liski thanks funding from the Nordic Energy Research Program and the Academy of Finland and Montero from Fondecyt Grant No. 1030961. 
permit trading has drawn increasing attention in the literature, and proposals to decrease emission caps over time suggest a particular larger role for banking in the future. The most prominent example is the US Acid Rain Program, where banking has been a major form of permit trading (Ellerman et al., 2000; Ellerman and Montero, 2005). During the first five years of the program constituting Phase I, 1995-99, only 26.4 million of the 38.1 million permits (or allowances) distributed were used to cover sulfur dioxide $\left(\mathrm{SO}_{2}\right)$ emissions. The remaining 11.65 million allowances (30\% of all the allowances distributed) were banked and have been gradually consumed during Phase II (2000 and beyond). As a result, the Phase II emissions cap is expected to be reached at some time between 2008 and 2010 .

Several authors have studied the theoretical properties of pollution permit banking (e.g., Rubin, 1996; Cronshaw and Kruse, 1996; Schennach, 2000), but there is little work on the effect of market power on the equilibrium banking path. ${ }^{1}$ We believe it is important to fill this gap not only for a better understanding of the performance of the existing markets for which banking is relevant but also for the better design (including permit allocations) of similar markets in the future. In that respect, the US Acid Rain Program appears as an interesting case study provided that we observe a substantial amount of banking and that large fraction of the permits are in the hands of few holding companies. An eventual carbon market with declining emission targets (and economic growth) is another relevant example. There are simulation studies documenting the possibility for large players (i.e., countries) to move the market away from the perfectly competitive outcome (e.g., Ellerman and Wing, 2000; Maeda, 2003), but these studies have adopted a static view of the problem in that firms are not allowed to trade permits intertemporally. It is not clear how those results would change with banking. The introduction of permit banking produce a significant increase in the liquidity of the market by making permits from previous vintages available for compliance in a given year. Some may argue that this market expansion would necessarily make the market more competitive while others may suggest the opposite, that banking creates opportunities for firms to expand their market power, for example, by buying large fractions of the overall permit stock.

\footnotetext{
${ }^{1}$ Hahn (1984) is the first to study market power in a permit market, but he considers a static context.
} 
These questions call for a more formal analysis. One of the few attempts in that direction is Liski and Montero (2004). ${ }^{2}$ They consider the presence of a large (polluting) firm or a cohesive cartel and a fringe of competitive firms and discuss the conditions that hold in equilibrium for very particular permits allocations. They find, for example, that a large firm receiving no stock allocation of permits (only a flow allocation) finds it optimal to follow competitive pricing during the banking path. That study, however, has some important limitations. It does not provide a general solution for the equilibrium path for any permits allocations and restricts the analysis to spot transactions.

In this paper, we build upon Liski and Montero (2004) and describe the subgameperfect equilibrium for any permit allocations between the large firm and the fringe. This benchmark model is then used to identify the effects of stock transactions (either by regulated firms or nonregulated outsiders), forward trading, and incomplete observability of (actual) permit holdings. These are features that we observe in the US $\mathrm{SO}_{2}$ trading program, and their implications for market power have not been analyzed before.

Because the evolution of the stock or bank of permits is closely related to the evolution of an exhaustible resource, we draw upon both the literature on permits markets and the literature on exhaustible resources to discuss whether and how the large (potentially dominant) firm can affect the equilibrium path. Yet, there are important differences between a permit market and a market for an exhaustible resource. For example, the permits market still remains after the permits bank has been exhausted while the market for an exhaustible resource vanishes after the total stock has been consumed. In addition, the demand for permits corresponds to a derived demand from the same firms that hold the permits while the demand for a typical exhaustible resource comes from a third party. This implies that firms have the opportunity to buy permits if they wish to increase their stock of permits; something that by construction is ruled out in depletable resource models. In any case, these differences make the intertemporal permit market unique and interesting.

\footnotetext{
${ }^{2}$ Hagem and Westskog (1998) also consider market power in an intertemporal permit market. However, their two-period approach could not be used to analyze the issues raised here. Using a multipleperiod horizon, Bernard et al.(2003) also introduce banking into a carbon trading regime but their equilibrium solution is based on a dynamic optimization approach that is quite different from our gametheorical approach.
} 
The rest of the paper is organized as follows. In Section 2, we develop a four-period model and limit attention to spot transactions. In Section 3, we explore how the equilibrium path found in Section 2 changes when firms can also be engaged in stock transactions (i.e., buy or sell permits beyond those needed or unneeded for current compliance). In Section 3, we study the effect of forward transactions on the equilibrium path. In Section 4, we discuss the implications of imperfect observability of firms stock holdings on the equilibrium path. Final remarks are in Section 5.

\section{The Model}

Since the permits bank is a depletable stock just like any other non-renewable resource, it is reasonable to believe that the equilibrium depletion path cannot be too different from the equilibrium path for a typical non-renewable resource. Thus, to find the banking equilibrium path we start by imposing the equilibrium characterization spelled out by Salant (1976) and then check that such characterization is indeed the equilibrium solution for the permit banking problem as well. The Salant's (1976) depletion path is characterized by two distinct phases. During the first or competitive phase numerous small firms (competitive fringe) deplete their stocks. During the second or monopoly phase, which starts right after the exhaustion of the fringe' stock, the single large firm (or cohesive cartel) is the only stockholder in the market. The banking path ends with the exhaustion of the large firm' stock. The long-run or after-banking equilibrium can also be subject to market manipulation by the large firm from the strategic choice of its abatement and permit sales/purchases (Hahn, 1984).

To study the exercise of market power during and after the banking period in the simplest way, we construct a four-period model $(t=1,2,3,4)$. The fringe is holding a permit stock in periods 1 and 2; the large firm is the monopoly stockholder in period 3; and the long-run (Hahn) equilibrium arrives in period 4 in which no stocks are left. Before explaining the four periods in detail, we introduce the allocations, technologies, and timing assumptions for the game.

The large firm (indexed by $m$ ) and the fringe (indexed by $f$ ) receive constant flow 
allocations $\left(a^{m}, a^{f}\right)$ per period. They also receive initial stock allocations denoted by $\left(s_{0}^{m}, s_{0}^{f}\right){ }^{3} \quad$ We rule out the borrowing of permits: current permit vintages as well as previous vintages in stocks can be saved for use in any later periods but future permits vintages cannot be used today. We adopt the convention that $s_{t}^{i}$ is the amount of stock held by group $i=m, f$ at the end of period $t$, i.e., after trading and emission decisions for period $t$ have been undertaken, stock $s_{t}^{i}$ is available in period $t+1$. We assume for now that individual stock holdings are publicly observed (later we relax this assumption). The amount of permits sold (bought) by $i$ in $t$ (a negative value indicates a net purchase) is denoted by $x_{t}^{i}$, and the market clearing price of permits in period $t$ is $p_{t}$. $r$ denotes the discount rate common to all firms.

In the absence of regulation, group $i$ 's unrestricted emissions are $u^{i}>a^{i}$ per period (the flow allocations are assumed to be binding). The aggregate abatement in period $t$ for group $i$ is denoted by $q_{t}^{i}$, so that emissions per period are $e_{t}^{i}=u^{i}-q_{t}^{i}$. We assume that total abatement costs of group $i$ is given by time-invariant abatement cost function $C_{i}\left(q_{t}^{i}\right)$, satisfying strict convexity assumptions: $C(0)=0, C_{i}^{\prime}\left(q_{t}^{i}\right)>0$, and $C_{i}^{\prime \prime}\left(q_{t}^{i}\right)>0$.

Let us now discuss the game between the two groups of agents, i.e., the large firm and the fringe. Both groups have rational expectations but only the large firm behaves strategically taking into account the effect of its own actions on the market equilibrium. Each firm in the fringe, on the other hand, is so small that it takes prices as given. Thus, we take the fringe as a rational-expectations, price-taking unit. We view the large firm as a Stackelberg leader in the sense that it moves first in each spot market $t$. More precisely, the large firm decides for period $t$ the number of permits $x_{t}^{m}$ to be sold (bought) in the market. The market does not observe its level of abatement $q_{t}^{m}$ (this is only observed at the end of the compliance period, i.e., after the spot market has cleared). But since the market can (perfectly) infer $q_{t}^{m}$ from the observation of $x_{t}^{m}$ and the current stock holdings, we can assume that both $q_{t}^{m}$ and $x_{t}^{m}$ are simultaneously chosen by the large firm.

Having observed the amount of permits offered (ordered) by the large firm, small

\footnotetext{
${ }^{3}$ The stock allocations can be created by a multi-period phase of generous flow allocations as in the U.S. Acid Rain program. Without losing any generality we do not explicitly model the initial saving phase of permits that leads to these initial stocks (see Liski and Montero, 2004).
} 
firms decide their abatement levels and trade to clear the permits market. While the market clearing price at $t$ will be directly related to the fringe's current abatement level $q_{t}^{f}$, the latter will, in turn, depend on the fringe's expectations about the evolution of the market in subsequent periods. For example, fringe members will make faster use of their stock of permits and abate less if they expect the future price of permits to drop in present value terms. Likewise, they will tend to hold onto their permits and abate more if they expect the future price to increase in present value terms. In equilibrium, fringe members correctly anticipate the evolution of market prices, hence, prices must exactly rise at the rate of interest during the period in which the fringe is holding a stock of permits.

The subgame perfect equilibrium of the game is found by backward induction. Hence, in what follows for the rest of the section we will first derive the equilibrium conditions after the exhaustion of the bank of permits (long-run equilibrium), then the equilibrium conditions when the only stockholder is the large firm (monopoly sotckholder phase), and finally, the equilibrium conditions when both the large firm and the fringe are holding stocks of permits (competitive phase).

\subsection{Long-run equilibrium}

We assume that the initial permit stocks are such that the long-term abatement goal is reached in period $t=4$. That is, the stock of permits is consumed within the first three

periods, so that in the fourth period, $e_{4}^{m}+e_{4}^{f}=a^{m}+a^{f}$. Then, if at the beginning of $t=4$, the large firm and the fringe have no stocks, $s_{3}^{m}=s_{3}^{f}=0$, the problem for the large firm is to maximize the net revenue from permit sales and compliance costs subject to the constraint that sales can be made only by abating more than what is the minimum abatement requirement $u^{m}-a^{m}$ in this period.

Although in reality the large firm offers $x_{4}^{m}$, its problem can be solved either by finding $x_{4}^{m}$ or $q_{4}^{m}$, i.e., the amount of abatement following an offer of $x_{4}^{m}$. We follow the latter route and state the problem as follows:

$$
\max _{q_{4}^{m}}\left[p_{4} x_{4}^{m}-C_{m}\left(q_{4}^{m}\right)\right]
$$


where

$$
\begin{gathered}
p_{4}=C_{f}^{\prime}\left(q_{4}^{f}\right) \\
x_{4}^{m}=q_{4}^{m}+a^{m}-u^{m} \\
x_{4}^{f}=q_{4}^{f}+a^{f}-u^{f} \\
x_{4}^{f}+x_{4}^{m}=0
\end{gathered}
$$

Equation (2) indicates that in equilibrium fringe members reduce emissions to the point where the cost of an extra unit of abatement is equal to the permits price. Eqs. (3) and (4) capture the full compliance status of all firms, and eq. (5) is a market clearing condition.

Using eqs. (2) through (5) to express $p_{4}$ (or $q_{4}^{f}$ ) and $x_{4}^{m}$ as functions of $q_{4}^{m}$, the first order condition for the above optimization problem can be written as

$$
C_{f}^{\prime}\left(q_{4}^{f}\left(q_{4}^{m}\right)\right)-x_{4}^{m}\left(q_{4}^{m}\right) \cdot C_{f}^{\prime \prime}\left(q_{4}^{f}\left(q_{4}^{m}\right)\right)=C_{m}^{\prime}\left(q_{4}^{m}\right)
$$

The LHS of (6) is the large firm's marginal revenue from selling an extra permit while the RHS is its marginal abatement costs. As explained by Hahn (1984), the large firm does not exercise any market power if in equilibrium it does not trade, i.e., $x_{4}^{m}=0$. This happens when the flow allocation $a^{m}$ coincides with the number of permits the large firm would have required in competitive equilibrium (at that point marginal revenues are exactly equal to marginal costs, so the large firm would incur in losses if either buy or sell permits). If $a^{*}$ denotes the "competitive" allocation for the large firm, setting $a^{m}>a^{*}$ implies that the large firm is a net seller withholding too many permits from the market and, thereby, distorting the permit price above the competitive level. For ease of exposition, we focus on the net seller case throughout the rest of the paper. ${ }^{4}$

\footnotetext{
${ }^{4}$ From arguments made below, it will become clear that is irrelevant whether the large firm is a seller or buyer of permits in the long-run.
} 


\subsection{Monopoly stockholder phase}

We consider now the last period of the banking phase, period 3, in which only the large firm is holding a stock. To see why it must be the case that the large firm is the sole stockholder in the end of a noncompetitive depletion path, recall that in competitive equilibrium prices would grow at the rate of interest as long as some stocks are left for the next period so that the competitive agents are willing to hold stocks to the end of the depletion path. Thus, if the competitive agents are the last stockholders, then the price path must be competitive throughout. In the noncompetitive stock-depletion equilibrium, the large firm is the last stockholder equalizing present-value marginal revenues across periods, implying that prices grow at a lower than the interest rate so that the competitive agents are indeed willing to exhaust their stocks before the monopoly stockholder phase. This decline in the present-value prices can occur only in the end of the path because of the fringe arbitrage (see also Salant, 1976; and Newbery, 1981).

At the beginning of $t=3$, the large firm has a stock of $s_{2}^{m}$ and the fringe has a stock of $s_{2}^{f}=0$, coming from the earlier period. Taking $s_{2}^{m}>0$ and $s_{2}^{f}=0$ as given, the large firm solves

$$
\pi_{3}^{m}\left(s_{2}^{m}\right)=\max _{q_{3}^{m}}\left[x_{3}^{m} p_{3}-C_{m}\left(q_{3}^{m}\right)\right]
$$

where

$$
\begin{gathered}
p_{3}=C_{f}^{\prime}\left(q_{3}^{f}\right) \\
x_{3}^{m}=s_{2}^{m}+q_{3}^{m}+a^{m}-u^{m} \\
x_{3}^{f}=q_{3}^{f}+a^{f}-u^{f} \\
x_{3}^{f}+x_{3}^{m}=0
\end{gathered}
$$

As in the fourth period, we first use eqs. (8)-(11) to express $p_{3}$ or $\left(q_{3}^{f}\right)$ and $x_{3}^{m}$ as functions of $q_{3}^{m}$ (and also of $s_{2}^{m}$ ), then obtain the first order condition for $q_{3}^{m}$

$$
C_{f}^{\prime}\left(q_{3}^{f}\left(q_{3}^{m}\right)\right)-x_{3}^{m}\left(q_{3}^{m}\right) \cdot C_{f}^{\prime \prime}\left(q_{3}^{f}\left(q_{3}^{m}\right)\right)=C_{m}^{\prime}\left(q_{3}^{m}\right)
$$

which is analogous to (6), and finally solve for the optimal $q_{3}^{m}$ as a function of $s_{2}^{m}$. 
Having obtained $q_{3}^{m}=q_{3}^{m}\left(s_{2}^{m}\right)$, we then obtain equilibrium values for $p_{3}\left(s_{2}^{m}\right)$ and $x_{3}^{m}\left(s_{2}^{m}\right)$. Replacing these equilibrium values in the objective function, we can define

$$
\pi_{3}^{m}\left(s_{2}^{m}\right)=p_{3}\left(s_{2}^{m}\right) \cdot x_{3}^{m}\left(s_{2}^{m}\right)-C_{m}\left(q_{3}^{m}\left(s_{2}^{m}\right)\right)
$$

as the subgame-perfect equilibrium profit that the large firm will obtain if the stocks

left at the end of the second period are $s_{2}^{f}=0$ and $s_{2}^{m}$. Recall, that this construction assumes that the price at $t=3$ is lower than the price at $t=2$ in present value terms (i.e., $p_{2}>p_{3} /(1+r)$ ), otherwise there would be no monopoly phase at $t=3$.

\subsection{Competitive phase}

We are now in the competitive phase where both the large firm and the fringe hold a stock of permits. Let us first consider the last period of this competitive phase, that is, period 2. At the beginning of $t=2$, the large firm has a stock of $s_{1}^{m}$ and the fringe has stock $s_{1}^{f}>0$. Because now the large firm must also decide about the amount of stock to be left for the third period, its sales $x_{2}^{m}$ is not only a residual determined by its abatement $q_{2}^{m}$, as in the last two periods. Therefore, taking $s_{1}^{m}$ and $s_{1}^{f}$ as given, the large firm chooses both $q_{2}^{m}$ and $x_{2}^{m}$ to solve

$$
\pi_{2}^{m}\left(s_{1}^{m}, s_{1}^{f}\right)=\max _{q_{2}^{m}, x_{2}^{m}}\left[x_{2}^{m} p_{2}-C_{m}\left(q_{2}^{m}\right)+\frac{\pi_{3}^{m}\left(s_{2}^{m}\right)}{1+r}\right]
$$

where

$$
\begin{gathered}
p_{2}=C_{f}^{\prime}\left(q_{2}^{f}\right) \\
s_{2}^{m}=s_{1}^{m}+a^{m}+q_{2}^{m}-x_{2}^{m}-u^{m} \\
s_{2}^{f}=s_{1}^{f}+a^{f}+q_{2}^{f}-x_{2}^{f}-u^{f}=0 \\
x_{2}^{f}+x_{2}^{m}=0
\end{gathered}
$$

and $\pi_{3}^{m}\left(s_{2}^{m}\right)$ is given by $(13)$.

The large firm's problem is to determine how much to save of its remaining stock $s_{1}^{m}$ to the next period. Intuitively, since the marginal revenue gives the opportunity cost of 
using permits for own compliance, the two should be equal in all periods. Moreover, if the marginal revenue in one period is higher than in other, the allocation of the stock usage over time can be improved. In Appendix A we show that the first order conditions for $q_{2}^{m}$ and $x_{2}^{m}$ are given by

$$
\begin{gathered}
-C_{m}^{\prime}\left(q_{2}^{m}\right)+\frac{C_{m}^{\prime}\left(q_{3}^{m}\right)}{1+r}=0 \\
C_{f}^{\prime}\left(q_{2}^{f}\right)-x_{2}^{m} C_{f}^{\prime \prime}\left(q_{2}^{f}\right)-\frac{C_{m}^{\prime}\left(q_{3}^{m}\right)}{1+r}=0
\end{gathered}
$$

Equilibrium condition (19) implies compliance cost minimization during the banking equilibrium: the large firm's marginal abatement costs rise at the rate of interest. Condition (20) implies that the marginal revenue from selling a permit is equal to the marginal cost of abatement. Combining the two implies that both marginal costs and revenues grow at the rate of interest during the banking phase.

Having found the subgame-perfect equilibrium values $q_{2}^{m}=q_{2}^{m}\left(s_{1}^{m}, s_{1}^{f}\right)$ and $x_{2}^{m}=$ $x_{2}^{m}\left(s_{1}^{m}, s_{1}^{f}\right)$, we can compute $p_{2}\left(s_{1}^{m}, s_{1}^{f}\right)$ and $s_{2}^{m}\left(s_{1}^{m}, s_{1}^{f}\right)$. Replacing these equilibrium values in the objective function we define

$$
\pi_{2}^{m}\left(s_{1}^{m}, s_{1}^{f}\right)=x_{2}^{m}\left(s_{1}^{m}, s_{1}^{f}\right) p_{2}\left(s_{1}^{m}, s_{1}^{f}\right)-C_{m}\left(q_{2}^{m}\left(s_{1}^{m}, s_{1}^{f}\right)\right)+\frac{\pi_{3}^{m}\left(s_{2}^{m}\right)}{1+r} .
$$

as the subgame-perfect equilibrium profit that the large firm will receive if the stocks left at the end of the first period are $s_{1}^{m}>0$ and $s_{1}^{f}>0$.

Finally, at the beginning of $t=1$, the large agent and the fringe have initial stocks of $s_{0}^{m}$ and $s_{0}^{f}$, respectively. Taking these stocks as given, the large agent solves

$$
\pi_{1}^{m}\left(s_{0}^{m}, s_{0}^{f}\right)=\max _{q_{1}^{m}, x_{1}^{f}}\left[x_{1}^{m} p_{1}-C_{m}\left(q_{1}^{m}\right)+\frac{\pi_{2}^{m}\left(s_{1}^{m}, s_{1}^{f}\right)}{1+r}\right]
$$

where

$$
\begin{gathered}
p_{1}=C_{f}^{\prime}\left(q_{1}^{f}\right) \\
s_{1}^{m}=s_{0}^{m}+a^{m}+q_{1}^{m}-x_{1}^{m}-u^{m}
\end{gathered}
$$




$$
\begin{gathered}
s_{1}^{f}=s_{0}^{f}+a^{f}+q_{1}^{f}-x_{1}^{f}-u^{f} \\
x_{1}^{f}+x_{1}^{m}=0 \\
p_{1}=\frac{p_{2}\left(s_{1}^{m}, s_{1}^{f}\right)}{1+r}
\end{gathered}
$$

Eq. (27) is a new condition that must hold in equilibrium. It imposes the rational expectations requirement that prices must exactly rise at the rate of interest if the fringe is expected to hold any positive amount of stocks for the next period.

The solution of (22) is a bit more involved than in previous periods because now the large firm is not facing a stationary demand by the fringe. In contrast to previous cases, selling more today makes the fringe to adjust its next period stock upwards since the spot markets in the two periods are connected by the fringe arbitrage. Therefore, to find equilibrium sales strategy we need to consider the spillover of sales from one period to another through the fringe banking. The solution technique to this problem is detailed in Appendix B. Despite the slightly more complicated calculation, the first order conditions for $q_{1}^{m}$ and $x_{1}^{m}$ are still as in the previous case:

$$
\begin{gathered}
-C_{m}^{\prime}\left(q_{1}^{m}\right)+\frac{C_{m}^{\prime}\left(q_{2}^{m}\right)}{1+r}=0 \\
C_{f}^{\prime}\left(q_{1}^{f}\right)-x_{1}^{m} C_{f}^{\prime \prime}\left(q_{1}^{f}\right)-C_{m}^{\prime}\left(q_{1}^{m}\right)=0 .
\end{gathered}
$$

These equilibrium conditions are identical to those holding for the second period, which allows us to conclude that the depletion path of the stock of permits is basically governed by three equilibrium conditions. The first condition is that permit prices must rise at the interest rate between periods in which the fringe is holding a stock of permits. The second condition is that the large firm equalizes the present value of marginal abatement costs along the entire depletion path. This condition simply implies that in equilibrium the large firm minimizes total abatement costs during the banking period (this cost minimization does not hold for fringe member because prices do not rise at the rate of interest throughout). And the third condition is that in all periods, the large firm sells permits up to the point where marginal revenues are exactly equal to marginal abatement costs. Given the close connection with the second condition, the third condition can be 
also interpreted as that in equilibrium the large firm's marginal revenues must rise at the rate of interest along the entire depletion path.

\subsection{Discussion}

In the subgame-perfect equilibrium that we have just characterized, the evolution of prices must satisfy

$$
\frac{p_{4}}{(1+r)^{3}}<\frac{p_{3}}{(1+r)^{2}}<\frac{p_{2}}{(1+r)}=p_{1}
$$

This price path does not necessarily hold for any arbitrary partition of the initial stock between the large firm and the fringe. Implicit constraints on stockholdings are needed to facilitate the four period exposition which we want to keep for simplicity. ${ }^{5}$ We illustrate these constraints as well as the nature of the equilibrium by the following numerical example. Let us assume that unrestricted emissions are $u^{m}=u^{f}=10$ and that flow allocations are $a^{m}+a^{f}=10$, so the regulator's long-term goal is to halve total emissions. To allow firms for a gradual transition to this long-term goal, the regulator provides a stock of 10 to be allocated between the large firm and fringe members. Abatement cost curves are $C_{f}\left(q^{f}\right)=\frac{1}{2}\left(q^{f}\right)^{2}$ and $C_{m}\left(q^{m}\right)=\frac{1}{2}\left(q^{m}\right)^{2}$. The discount rate is $r=0.5$.

Figure 1 shows the time paths for prices, marginal costs, spot sales, and stocks in two cases. In the first case, firms are symmetric in all respects but in two: the large firm or the cartel has a larger flow allocation and a larger share of the initial stock $(70 \%$ of both allocations). Note that for this division of stocks, the equilibrium satisfies the restrictions imposed in our construction $\left(s_{3}^{m}=s_{4}^{m}=s_{2}^{f}=s_{3}^{f}=s_{4}^{f}=0\right) .{ }^{6}$ The equilibrium paths are depicted by the solid lines.

The second case is the same as the first except that the long-run allocation is efficient, $a^{m}=a^{*}$, so that there are no distortions in the final stage. The equilibrium paths are depicted by the dotted lines for this case.

Let us now discuss the qualitative features of the equilibrium paths. The price grows

\footnotetext{
${ }^{5}$ If the implicit restrictions on stockholdings are not satisfied, it is not possible to have this characterization of equilibrium in four periods. Thus, the equilibrium number of periods depends on the intial stocks, which we have implicitly chosen such that our four period example works.

${ }^{6}$ In fact, for these parameters, the equilibrium has the depicted qualitative features as long as the large firm has more than $38.8 \%$ of the initial stock.
} 
at the rate of interest between first two periods $\left(1.5 p_{1}=p_{2}\right)$ and at a strictly lower rate between $t=2$ and 3 , as expected. If $a^{m}>a^{*}$, the fourth period price is higher than the competitive price (denoted by $p_{c}$ in the graph), since the allocations imply that the large firm is the net seller in the absence of permit stocks. If $a^{m}=a^{f}$, then the long-run price is the competitive price, which lowers the price path throughout the equilibrium, as depicted.

Note that the large firm has a lower marginal cost throughout the banking equilibrium because it is shifting the abatement burden towards the fringe; the marginal cost of the latter equals the manipulated price whereas the large firm's marginal cost equals the marginal revenue from sales which is lower than the price (which holds for all periods). The northeastern panel illustrates how the distortion suffered by the fringe's abatement efforts during the banking phase decreases when the long-run market power is eliminated.

The sales path $x^{m}$ that keeps the marginal revenue growing at the rate of interest during banking is first increasing and then declining. When the flow allocation is reduced to $a^{m}=a^{*}$, sales during banking go down because the leader has a lower share of the overall allocation (stock and flow together). Thus, when the long-run equilibrium is competitive, the leader uses more of the stock for own compliance.

Finally, the last panel shows that the depletion of stocks is faster when the equilibrium becomes more competitive, i.e., when the leader's flow allocation is reduced to $a^{m}=a^{*}$.

Throughout the rest of the paper we use this equilibrium as our benchmark, so it proves useful to summarize its properties.

Proposition 1 The properties of the manipulated banking path as implied by the benchmark model are the following:(i) the competitive stockholdings are exhausted before the noncompetitive holdings;(ii) prices must ultimately decline in present value $\left(p_{2}(1+r)>\right.$ $\left.p_{3}\right)$;(iii) the fringe does not equalize present-value marginal costs across all periods whereas the large firm does; (iv) the long-term market power as identified by Hahn (1984) is extended to the banking phase. ${ }^{7}$

\footnotetext{
${ }^{7}$ The last point of the proposition has been shown also in Liski and Montero (2004) who consider only two extreme permit allocations.
} 

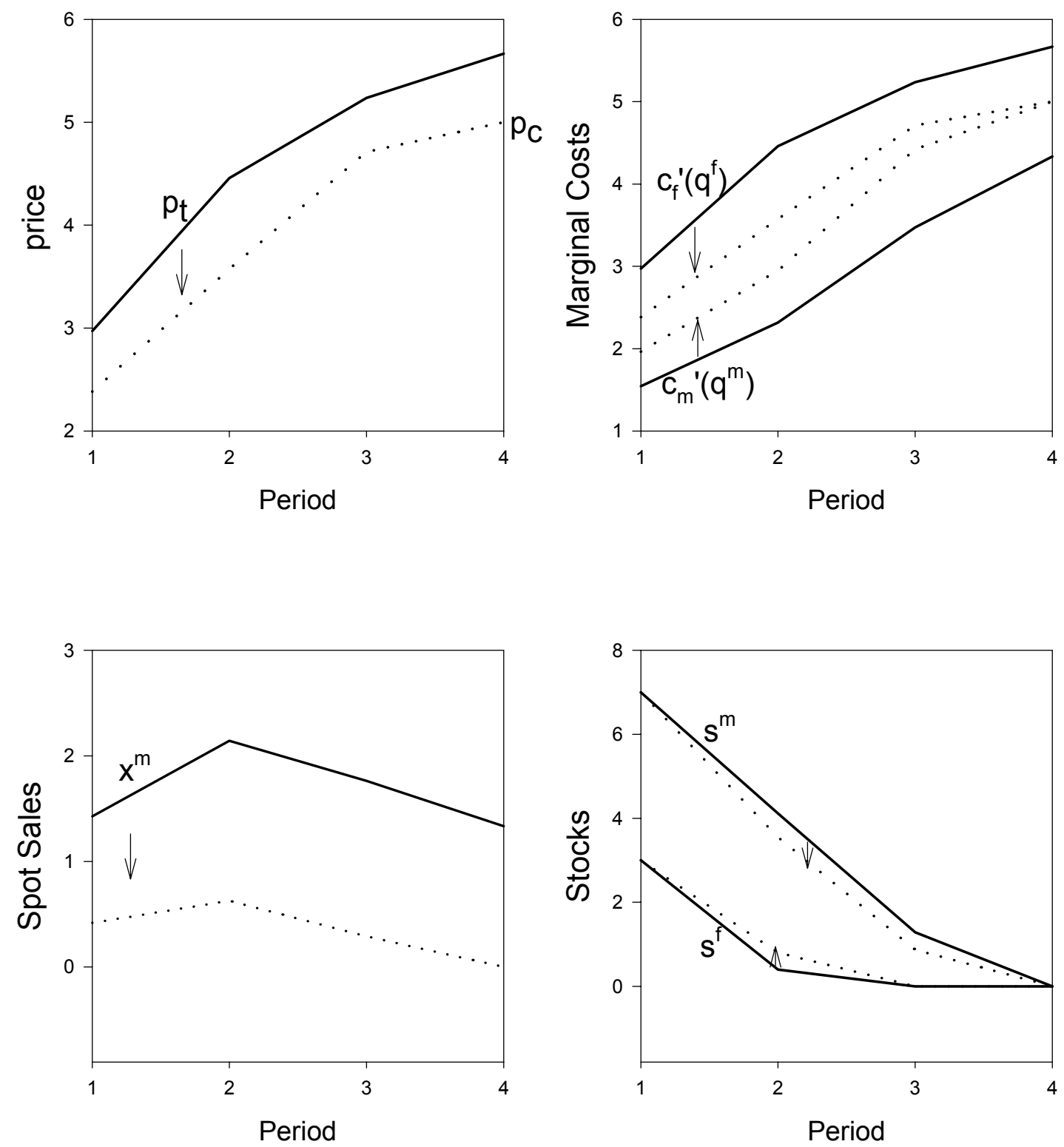

Figure 1: Solid lines are subgame-perfect equibrium paths for prices, marginal abatement costs, sales, and stocks for the following parameter values: $a^{m}=7, a^{f}=3, u^{m}=u^{f}=10$, $s_{0}^{m}=7$, and $s_{0}^{f}=3$. Dotted lines are equilibrium paths for the the long-run competitive allocation $\left(a^{m}=a^{f}=5\right)$ and the rest of the parameters as above. 


\section{$3 \quad$ Imperfectly Observed Stockholdings}

In permit trading programs the regulator typically runs a computerized "permit (allowance) tracking system" (as in the U.S. Acid Rain program) which together with accurate measuring of emissions makes it easy to monitor the compliance status of the regulated firms: each firm should have enough permits in its account with the tracking system to cover its emissions over the compliance period (typically a year). While one purpose of the tracking system is to provide the information about the compliance of the regulated firms, a by-product of a transparent tracking system is that the regulated firms as well as third parties (traders in the permit market) can in principle observe other traders' permits in the tracking system. However, in reality, actual permit holdings can be easily masked by using middlemen such as permit brokers since permit accounts can be opened not only for the regulated firms but also for outsiders which are nonaffected by the regulation. Thus, even in the presence of a permit tracking system, it is unreasonable to think that permit holdings by private entities are fully observed by the market. In this section we discuss how relaxing full observability of private stockholdings affects the ability to manipulate the permit banking program.

Let us consider our benchmark model and the example depicted in Figure 1 to illustrate that (i) the equilibrium solution puts an explicit constraint on stockholdings along the equilibrium path and that (ii) there is a natural tendency to deviate from this constraint if permit holdings are not observed. In the first period, the fringe is abating $q_{1}^{f}=2.972$ and buying $x_{1}^{m}=1.428$ units, so the fringe uses $u^{f}-a^{f}-q_{1}^{f}-x_{1}^{m}=2.6$ units

from its stock $\left(s_{0}^{f}=3\right)$ in the first period. These numbers are $q_{2}^{f}=4.458, x_{2}^{m}=2.142$, and $u^{f}-a^{f}-q_{2}^{f}-x_{2}^{m}=0.4$ for period 2. Recall that a requirement of the competitive phase is that prices grow at the rate of interest, which means that the fringe's marginal cost must grow at this rate. Then, we could conjecture that the above equilibrium remains the same if we keep the abatement choices the same $\left(q_{1}^{f}, q_{2}^{f}\right)=(2.972,4.458)$, so that the marginal costs remain the same, and change the traded quantities such that, say, $x_{1}^{m}=1.428-0.3$ and $x_{2}^{m}=2.142+0.3$. This change only makes the fringe to consume more of its stock in period $t=1$ and rely on a larger purchase in period $t=2$. Because the fringe still exhausts its stock in period $t=2$ and prices grow at the rate 
of interest between $t=1$ and $t=2$, it seems that the change in the traded quantities can be made without affecting the equilibrium outcome. And if this change is legitimate, then it seems that the quantities traded between the fringe and the large firm can be quite arbitrarily chosen, as long as the arbitrage condition on prices and the exhaustion condition on stocks are satisfied.

However, changing the trading levels as explained above is not consistent with the requirement that the equilibrium should be subgame perfect: if the large firm's sales in the first period are reduced to $x_{1}^{m}=1.128$, then the large firm has a larger and the fringe has a smaller stock at $t=2$ than along the benchmark equilibrium, implying that the large firm's choices for abatement and sales, given by $q_{2}^{m}\left(s_{1}^{m}, s_{1}^{f}\right)$ and $x_{2}^{m}\left(s_{1}^{m}, s_{1}^{f}\right)$, will differ from those chosen along the benchmark path. In fact, this change would imply that the large firm becomes larger at $t=2$ so that it becomes more dominant. If, on the other hand, we changed the trading pattern such that the fringe buys more at $t=1$ and less at $t=2$ from the large firm, then the subgame-perfect equilibrium outcome starting from $t=2$ would become more competitive.

Subgame-perfection thus requires that the stocks $\left(s_{t}^{m}, s_{t}^{f}\right)$ develop in right proportions along the equilibrium path which, in turn, fixes a unique trading pattern between the large firm and fringe. The above-discussed deviations from the equilibrium trading pattern correspond to the situation where the large firm can make stock purchases or sales at very lucrative prices. Selling less than $x_{1}^{m}\left(s_{0}^{m}, s_{0}^{f}\right)$ in our example implies that the large firm is effectively buying stocks for the period $t=2$ at prices which are lower than the true equilibrium prices. Selling more than $x_{1}^{m}\left(s_{0}^{m}, s_{0}^{f}\right)$ corresponds to the case where the large firm is able to sell stocks at $t=1$ at prices higher than the true equilibrium prices.

Subgame perfection together with the full observability of private permit holdings puts therefore an explicit constraint on the path for the stockholdings - the large firm cannot profitably implement a deviation from the subgame-perfect equilibrium stockdepletion path because the market can fully foresee the changes in subsequent behavior which, in turn, implies that the current prices will respond in an unfavorable way. It is important to emphasize that the implications of this model for market power crucially depend on the fact that market participants can monitor how the stockholdings of the 
large firm develop. We do not have a model for the situation where private stockholdings are incompletely observed, but the logic of market manipulation under full observability suggests that incomplete observability implies a credibility problem for the large firm. Let us now conclude this section by explaining this credibility problem.

Recall that the permit banking path is manipulated by shifting the large firm's sales to later periods (period $t=3$ in our benchmark model) such that the present-value prices for permits ultimately decline, which makes the competitive stockholders willing to exhaust their stocks during the early periods of the banking phase (periods $t=1,2$ in our model). As a result, the value of the competitive stockholdings increase, so the fringe is free riding on the large firm's market power. Under full observability the large firm has no way of extracting these free riding rents, but under incomplete observability there is a tendency to do so. To illustrate this possibility, suppose the market cannot fully observe the identity of permit suppliers in the permit spot market but, for some reason, still believes in the benchmark equilibrium path for prices and quantities. In this situation, the market cannot observe that the large firm is actually saving part of its stock for the monopoly phase whose existence is necessary for the conjectured prices. In fact, if the market is believing that the monopoly phase will exist, but cannot observe how the stocks are depleted, the large firm would have incentives to "hide" behind the fringe and sell more during the competitive phase in order to take advantage of higher initial prices (recall that $\left.p_{1}>p_{3} /(1+r)^{2}\right)$. In anticipation of these deviation incentives, the equilibrium should become more competitive. We leave it open for future research whether this depletable-stock market can be manipulated at all under incomplete information about stockholdings.

\section{Stock Transactions}

Initial permit stocks imply a potentially dramatic increase in the liquidity of the permit market. There are simply too many permits to be used for compliance in the early periods. This in turn implies that a market participant can in principle withhold a larger permit allocation from a spot market than in the long-run when all stocks are exhausted. Since 
permit stocks typically exist in electronic accounts with zero storage costs, it is natural ask if these easily movable stocks can be purchased in order to gain market power. Moreover, because anyone can buy and hold permits, we consider whether the possibility of stock transactions makes the permit market or its banking phase vulnerable to manipulation by an outsider who has no initial permit allocation and abatement targets. Stock trading also raises the possibility that a large firm or cohesive cartel monopolizes the market further by increasing its share of the overall stock.

Our benchmark model defines the payoffs achievable from holdings $\left(s_{0}^{m}, s_{0}^{f}\right)$ for the large stockholder and fringe. This Stackelberg game assumes that the holding for the leader is large enough to justify the ability to move first in each period of the game. Next we open up the market for stocks such that stocks can be traded before the above Stackelberg game is played. This allows us to analyze whether a large regulated firm can improve its leader position in the game or whether an outsider nonaffected by the regulation can achieve the leader position by buying stocks.

Proposition 2 Given rational expectations and full information, neither a large regulated firm or nonregulated outsider can profitably purchase stocks to gain (further) market power.

Proof: We consider the regulated firm first since the problem for the outsider follows as a special case. Let

$$
\pi_{1}^{m}\left(s_{0}^{m}, s_{0}^{f}\right)=x_{1}^{m}\left(s_{0}^{m}, s_{0}^{f}\right) p_{1}\left(s_{0}^{m}, s_{0}^{f}\right)-C_{m}\left(q_{1}^{m}\left(s_{0}^{m}, s_{0}^{f}\right)\right)+\frac{\pi_{2}^{m}\left(s_{1}^{m}, s_{1}^{f}\right)}{1+r}
$$

denote the first-period profit defined as a function of initial holdings $\left(s_{0}^{m}, s_{0}^{f}\right)$, as explained in the analysis of our benchmark model. We are interested in finding out whether the holdings $\left(s^{m}, s^{f}\right)=\left(s_{0}^{m}, s_{0}^{f}\right)$ are in fact the large firm's preferred holdings in the presence of a market for stocks. Without losing generality of the argument, we assume that trading with stocks takes place before the Stackelberg game defining the payoff $\pi_{1}^{m}\left(s_{0}^{m}, s_{0}^{f}\right)$ is played. The large firm's problem is to choose a division of stocks to

$$
\max _{s^{m}}\left[\pi_{1}^{m}\left(s^{m}, s_{0}-s^{m}\right)-p_{1}\left(s^{m}, s_{0}-s^{m}\right) \cdot\left(s^{m}-s_{0}^{m}\right)\right]
$$


given $s_{0}=s_{0}^{m}+s_{0}^{f}$, where $p_{1}$ is the rational-expectations price at the first period of the game starting with the chosen division of stocks, $\left(s^{m}, s^{f}\right)$. That is, holding $s^{m}$ can be increased above $s_{0}^{m}$ by paying unit price $p_{1}$ that the market is expecting to prevail when the Stackelberg game is played. In Appendix B we solve the large firm's problem in period $t=1$ and show that the shadow value of the fringe stock in equilibrium satisfies

$$
\mu=\frac{\partial}{\partial s_{0}^{f}} \pi_{1}^{m}\left(s_{0}^{m}, s_{0}^{f}\right)=-x_{1}^{m} C_{m}^{\prime \prime}\left(q_{1}^{m}\right)<0
$$

The shadow value of the leader's own stock satisfies

$$
\lambda=\frac{\partial}{\partial s_{0}^{m}} \pi_{1}^{m}\left(s_{0}^{m}, s_{0}^{f}\right)=C_{f}^{\prime}\left(q_{1}^{f}\right)-x_{1}^{m} C_{m}^{\prime \prime}\left(q_{1}^{m}\right),
$$

which in equilibrium equals the marginal revenue from sales. The marginal effect of increasing the large firm's holding $s^{m}$ through stock trading is

$$
\begin{gathered}
\frac{\partial}{\partial s^{m}} \pi_{1}^{m}\left(s^{m}, s^{f}\right)-\frac{\partial}{\partial s^{f}} \pi_{1}^{m}\left(s^{m}, s^{f}\right)-p_{1}-\frac{\partial}{\partial s^{m}} p_{1} \cdot\left(s^{m}-s_{0}^{m}\right)= \\
-\frac{\partial}{\partial s^{m}} p_{1} \cdot\left(s^{m}-s_{0}^{m}\right)
\end{gathered}
$$

which is negative when $\left(s^{m}, s^{f}\right)=\left(s_{0}^{m}, s_{0}^{f}\right)$, by $(32),(33)$, and the fact that $\frac{\partial}{\partial s^{m}} p_{1}>$ 0 (making the division of stocks less competitive increases the price level). Thus, a regulated large firm does not prefer to increase its holdings. In fact, it would prefer to reduce holdings since adding the stock trading stage to the game is just like adding one more sales period which, of course, will be used.

The proof for a nonregulated outsider requires the following modifications. First, $\left(s_{0}^{m}, s_{0}^{f}\right)=\left(0, s_{0}\right)$, implying that the banking path is competitive in the absence of any takeover of the permit bank. Second, the outsider has no abatement target, so $q_{t}^{m}=0$ as well as $a^{m}=0$. These changes imply that we are left with the Salant's (1976) description for market power in a depletable-stock market. Thus, if stock $s^{m}>0$ is purchased and used for market manipulation, then marginal revenues from selling from this stock satisfies

$$
p_{1}-x_{1}^{m} C_{f}^{\prime \prime}\left(q_{1}^{f}\right)=\frac{1}{1+r}\left[p_{2}-x_{2}^{m} C_{f}^{\prime \prime}\left(q_{2}^{f}\right)\right]=\frac{1}{1+r}\left[p_{3}-x_{3}^{m} C_{f}^{\prime \prime}\left(q_{3}^{f}\right)\right]
$$


which assumes that $s^{m}$ is sold in three periods. Since the marginal revenue at $t=1$ gives the present-value shadow value of having one more unit of $s^{m}$ to be sold in any of the periods $t=1,2,3$, it cannot be profitable to buy stocks with price satisfying $p_{1}>$ $p_{1}-x_{1}^{m} C_{f}^{\prime \prime}\left(q_{1}^{f}\right)$. This reasoning holds irrespective of the number of periods considered.

The intuition for the result follows from the observation that the competitive fringe is free riding on the large stockholder's market power. Consider the case where the large stockholder is an outsider who, for some exogenous reason, has stock $s^{m}$ which is sold in three periods in equilibrium. For the equilibrium to be noncompetitive, the fringe cannot be selling in the last period. This implies that the last period $(t=3)$ price is lower in present value than the first-period price

$$
p_{1}>\frac{p_{3}}{(1+r)^{2}}
$$

We observe that it is optimal for the large seller to let the fringe exhaust first and be the only one selling at $t=3$. Although at $t=3$ units are sold at a lower price in present value terms (which explains the fringe's absence), at the margin the large seller receives the same revenue for these units that for those sold at $t=1$ and 2 . Thus, the large stockholder moves the market by shifting sales to the third period in exchange for an increase in today's prices. Of course, the asset values for the fringe increase due to the presence of the large seller. This is why the fringe is free riding on the large stockholder's market power, given the large holding $s^{m}$. If the large firm does not receive the stock as an initial allocation, $s^{m}=s_{0}^{m}$, it is not profitable to buy this stock from competitive stockholders: the market price for stocks acquired is the ex-post noncompetitive price which fully appropriates the gains from market manipulation.

The result has an analog in the shareholder takeover literature (Grossman and Hart (1980) and, e.g, Holmström and Nalebuff, 1992). An outsider can be interpreted as a raider making a tender offer for permit stocks. Because in reality permit purchases can be made during a considerable period of time and stockholdings potentially easily masked by using middlemen, the takeover may not be fully anticipated and, therefore, the gains from it may not be fully appropriated by the market. Although our result is limited in the sense that it depends on the assumption of full information, it is important to observe 
that an insider (a regulated firm) having long-term market power cannot gain from his long-term position to increase the noncompetitive stockholding.

\section{$5 \quad$ Forward Trading}

Since abatement strategies often involve long-term investments, for example, in energy production capacity and supply infrastructure and in contracting decisions for inputs that are complements or substitutes for permits, it is natural to expect a development of an active futures market for permits. Our prime example, the US market for $\mathrm{SO}_{2}$ emissions, provides salient evidence of such a development in the form of active options, futures, and "swaps" market (Joskow, Schmalensee, and Bailey, 1998; Ellerman et al. 2000).

While it cannot be directly observed what fraction of the current permit stocks in the US $\mathrm{SO}_{2}$ program has already been sold in the forward market or otherwise affected by the futures trading 8 , our point of departure in this section is the observation that there exists a futures market for permits and that stocks are actively sold forward. ${ }^{9}$

In this section our objective is to demonstrate that the typical approach to market power in a depletable-stock market that we used in our benchmark analysis, is not consistent with an active forward market for permits. In fact, the implications for market manipulation are critically dependent on the assumption that permit trading is restricted to spot transactions. While our benchmark model could be extended to the case where firms in each period $t$ not only sell on the spot market but also trade future delivery contracts, we do not consider the full subgame-perfect equilibrium for such a game. ${ }^{10}$ Our purpose is only to demonstrate that forward trading is not in the interests of the large firm since it necessarily leads to a more competitive outcome.

\footnotetext{
${ }^{8}$ The US EPA runs a computerized allowance tracking system that makes current "physical" holdings of each firm visible to all market participants. However, the system does not reveal whether the current holding has been sold forward, so in this sense the system does not directly keep track of actual holdings.

${ }^{9}$ Personal communication with Denny A. Ellerman, MIT Center for Energy and Environmental Policy Research.

${ }^{10}$ Allaz and Vila (1993) assume that there is at least one forward sale before the production stage in a Cournot oligopoly. The same approach could be used here, although our set-up is slightly more complicated since there are several "production" stages. For the extension of Allaz and Vila to this direction, see Liski and Montero (2004).
} 
For this purpose, assume that at $t=1,2,3,4$ the timing in the spot market is the same as previously. That is, the large firm is a Stackelberg leader choosing its abatement and demand for permits before the fringe. Assume also that at $t=1$ there is a forward-market opening in which market participants can take short and long positions for deliveries in $t=2$. More specifically, a forward contract signed at $t=1$ specifies a dated commodity (permit) that remains in seller's stock until the date of delivery is reached. The price for the delivery is made (or formally contracted) at $t=1$. Let $f_{1}^{i}(2)$ for $i=m, f$ denote the quantity of forward sales made at $t=1$ for period 2 . We assume that participants in the forward market (other regulated firms, speculators) have rational expectations. There is also full information about the short positions taken by the stockholders, $f_{1}^{m}(2)$ and $f_{1}^{f}(2) .{ }^{11}$ While we do not explicitly consider the price formation process in the forward market, forward supplies lead to downward pressure in the forward price and thereby to speculatory demand; the equilibrium price for forward deliveries will be bid to equal the expected (discounted) spot price in period $t=2$ (see Allaz and Vila, 1993) We assume that the large firm chooses its forward position first, simultaneously with is abatement and permit demand decisions.

The expected spot price in period $t=2$ and, hence the forward price in period $t=1$, must be obtained by considering whether forward contracting changes the large firm's behavior in period $t=2$. The relevant question is then the following: do $q_{2}^{m}\left(s_{1}^{m}, s_{1}^{f}\right)$ and $x_{2}^{m}\left(s_{1}^{m}, s_{1}^{f}\right)$ obtained for the benchmark model still describe the subgame-perfect strategies given the holdings $\left(s_{1}^{m}, s_{1}^{f}\right)$, despite the possibility that part of the stocks may have been already sold before period $t=2$ arrives? To test this, note that having contracted $f_{1}^{m}(2)$ of its sales for period $t=2$ the large firm's problem is to solve

$$
\max _{q_{2}^{m}, x_{2}^{m}}\left[p_{2} \cdot\left(x_{2}^{m}-f_{1}^{m}(2)\right)-C_{m}\left(q_{2}^{m}\right)+\frac{\pi_{3}^{m}\left(s_{2}^{m}\right)}{1+r}\right]
$$

subject to constraints (15)-(18). Note that $x_{2}^{m}$ still denotes the overall deliveries in period 2, so that $x_{2}^{m}-f_{1}^{m}(2)$ gives the spot market sales. It is immediately clear that

\footnotetext{
${ }^{11}$ This is not entirely realistic assumption because forward positions are typically anonymous. However, relaxing the observability assumption should only strengthen our conclusions since the effect should be pro-competitive, as we will explain below.
} 
the large firms marginal revenue from sales in period $t=2$,

$$
p_{2}-\left(x_{2}^{m}-f_{1}^{m}(2)\right) \cdot C_{f}^{\prime \prime}\left(q_{2}^{f}\right),
$$

jumps up as a result of forward trading because the revenue from sales $f_{1}^{m}(2)$ is already secured. Selling more than $x_{2}^{m}\left(s_{1}^{m}, s_{1}^{f}\right)$ in period 2 becomes profitable, leading to more competitive stock depletion. Because participants in the forward market foresee how the incentives for spot sales by the large firm are altered by forward contracting, they rationally expect a forward price that is lower than our benchmark spot price; the price is lower, the greater the quantity of sales contracted forward by the large firm.

The above reasoning shows, without specifying what determines the demand for forward contracting, that the large firm cannot make forward sales without reducing its payoff. One might argue that selling the entire stockholding forward would avoid the problem because, if the large firm has no "uncommitted" stock left, it cannot flood the spot market with additional supplies. To test this argument, we would have to allow for additional forward market openings. Suppose that the forward market at $t=1$ allows forward sales to periods $t=2,3$, and at $t=2$ to period $t=3$. Assume then that the first forward position for the large firm is "full" in the sense that

$$
f_{1}^{m}(2)+f_{1}^{m}(3)=s_{0}^{m}-x_{1}^{m} .
$$

That is, the stock remaining after the first spot sale is fully offered to the forward market. Suppose that this forward trading strategy solves the large firm's credibility problem discussed above. Then, given this conjecture, our benchmark spot prices identify the forward prices with which the large firm can make the forward sales. However, these prices are declining in present value after period 2 (see (30)), which creates an arbitrage opportunity for the large firm: the firm can buy back its deliveries for period $t=3$ to make additional sales in period $t=2$.

The arbitrage can be implemented as follows. When period 2 forward market opens, the large firm takes a long position for deliveries in $t=3$. This reduces the large firm's delivery commitments to period $t=3$ below the original forward sales $f_{1}^{m}(3)$, making 
it possible to sell more in spot market $t=2$ (recall that the firm is still holding the stocks from which the commitments to period $t=3$ were made). This deviation from the original plan implies a reduction in the spot price below the conjectured spot price at $t=2$ and losses on those who bought delivery contracts $f_{1}^{m}(2)$ at the conjectured price. Thus, the conjectured price path cannot be an equilibrium path. In fact, when the large firm sells the entire stockholding forward, the equilibrium price path must have a competitive shape: if prices are declining in present value terms, which is a property of a noncompetitive price path, then the above discussed arbitrage opportunities must exist. We can now summarize these findings.

Proposition 3 Forward-market opening does not change the large firm's sales behavior. That is, in subgame-perfect equilibrium all sales are made in the spot market.

Proof: Follows from the discussion above.

The result implies that if we observe extensive forward trading by the "suspected" market participant, then this participant should not be involved in market manipulation. In other words, because the large firm can commit to its original marginal revenue from permit sales and, thereby, to its maximum profits by avoiding forward sales, we should not observe forward trading by the large firm. There are, of course, limitations to this argument. First, there might be hedging or other reasons for the existence of a demand for forwards, so the large firm may want to sacrifice part of its market power to satisfy this demand. Second, if forward positions are anonymous in the sense that the market observes only the aggregate forward position, the large firm may not be able to communicate to the market that it has not altered the position of its marginal revenue curve by making forward sales. We do not have a model for this incomplete information situation but suspect that the equilibrium outcome must become more competitive due to the lack of information regarding the identity of sellers in the forward market. ${ }^{12}$

\footnotetext{
${ }^{12}$ If observability is limited, there is always a possibility that the large firm serves a spot market many times, which implies losses on contract holders unless prices are adjusted downwards at the outset to take the deviation possiblities into account.
} 


\section{Conclusions}

We have investigated the effect of market power on the equilibrium path of an emission permit market in which firms bank current permits for gradual use in later periods. In particular, we have studied the equilibrium for a large (potentially dominant) firm and a competitive fringe with rational expectations. When permit trading is limited to spot transactions, we characterized a subgame-perfect equilibrium in which the large firm can credibly manipulate the permit banking program. The results imply that the ability to move the banking path depends not only on the size of the stockholding but also on the long-run market power depending on long-run allocations. This property makes the intertemporal permit market different from previously analyzed depletable-stock markets.

Using the above benchmark equilibrium we considered how the ability to manipulate the permit banking program is affected by three changes in assumptions that reflect important features of existing permit trading programs. First, we found that trading with permit stocks does not make the permit market more vulnerable to manipulation. Second, an active forward market implies that the full gains from market power achievable under pure spot transactions cannot exist. Third, imperfectly observed permit holdings imply a potential credibility problem for the large firm, making the market again more competitive, as compared to the benchmark outcome. Thus, all these "real world" observations have pro-competitive implications, leading us to conclude that manipulating a permit banking program may be a very difficult undertaking even for a large permit stockholder.

\section{Appendix A}

Taking $s_{1}^{f}$ and $s_{1}^{m}$ as given, the large firm solves (14) subject to (15)—(18). Replacing $p_{2}=C_{f}^{\prime}\left(q_{2}^{f}\right)$ into the objective function, the first order conditions for $q_{2}^{m}$ and $x_{2}^{m}$ are, respectively (recall that $s_{2}^{f}=0$ by assumption)

$$
x_{2}^{m} C_{f}^{\prime \prime}\left(q_{2}^{f}\right) \frac{\partial q_{2}^{f}\left(q_{2}^{m}, x_{2}^{m}\right)}{\partial q_{2}^{m}}-C_{m}^{\prime}\left(q_{2}^{m}\right)+\frac{1}{1+r} \frac{d \pi_{3}^{m}\left(s_{2}^{m}\left(q_{2}^{m}, x_{2}^{m}\right)\right)}{d s_{2}^{m}} \frac{\partial s_{2}^{m}}{\partial q_{2}^{m}}=0
$$




$$
C_{f}^{\prime}\left(q_{2}^{f}\right)+x_{2}^{m} C_{f}^{\prime \prime}\left(q_{2}^{f}\right) \frac{\partial q_{2}^{f}\left(q_{2}^{m}, x_{2}^{m}\right)}{\partial x_{2}^{m}}+\frac{1}{1+r} \frac{d \pi_{3}^{m}\left(s_{2}^{m}\left(q_{2}^{m}, x_{2}^{m}\right)\right)}{d s_{2}^{m}} \frac{\partial s_{2}^{m}}{\partial x_{2}^{m}}=0
$$

From (17) and (18) we know that $q_{2}^{f}\left(q_{2}^{m}, x_{2}^{m}\right)=-x_{2}^{m}+u^{f}-a^{f}-s_{1}^{f}$, so $\partial q_{2}^{f} / \partial q_{2}^{m}=0$ and $\partial q_{2}^{f} / \partial q_{2}^{m}=-1$. Similarly, (16) gives the expression for $s_{2}^{m}\left(q_{2}^{m}, x_{2}^{m}\right)$, so $\partial s_{2}^{m} / \partial q_{2}^{m}=1$ and $\partial s_{2}^{m} / \partial x_{2}^{m}=-1$.

To obtain $d \pi_{3}^{m}\left(s_{2}^{m}\right) / d s_{2}^{m}$, let us rewrite (13) as

$$
\pi_{3}^{m}\left(q_{3}^{m}\left(s_{2}^{m}\right), s_{2}^{m}\right) \equiv \pi_{3}^{m}\left(s_{2}^{m}\right)=x_{3}^{m}\left(q_{3}^{m}, s_{2}^{m}\right) \cdot C_{f}^{\prime}\left(q_{3}^{f}\left(q_{3}^{m}, s_{2}^{m}\right)\right)-C_{m}\left(q_{3}^{m}\right)
$$

where $q_{3}^{m}\left(s_{2}^{m}\right)$ is the solution to (7) for any given $s_{2}^{m}$. Then, from the envelope theorem we have

$$
\frac{d \pi_{3}^{m}\left(s_{2}^{m}\right)}{d s_{2}^{m}}=\frac{\partial x_{3}^{m}}{\partial s_{2}^{m}} C_{f}^{\prime}(\cdot)+x_{3}^{m} \cdot C_{f}^{\prime \prime}(\cdot) \frac{\partial q_{3}^{f}}{\partial s_{2}^{m}}
$$

And since $\partial x_{3}^{m} / \partial s_{2}^{m}=1$ from (9) and $\partial q_{3}^{f} / \partial s_{2}^{m}=-1$ from the combination of (9), (9) and $s_{2}^{f}=0$, eq. (37) becomes $d \pi_{3}^{m}\left(s_{2}^{m}\right) / d s_{2}^{m}=C_{f}^{\prime}\left(q_{3}^{f}\right)-x_{3}^{m} C_{f}^{\prime \prime}\left(q_{3}^{f}\right)$. In addition, using the first order condition (12), yields

$$
\frac{d \pi_{3}^{m}\left(s_{2}^{m}\right)}{d s_{2}^{m}}=C_{m}^{\prime}\left(q_{3}^{m}\right)
$$

Finally, replacing (38) and the above partial derivatives into (35) and (36), the first order conditions reduce to (19) and (20) in the text.

\section{Appendix B}

Taking $s_{0}^{m}$ and $s_{0}^{f}$ as given, the large firm must solve (22) subject to (23)-(27). Using (26) and (27), we can rewrite the large firm's optimization problem as

$$
\max _{q_{1}^{m}, x_{1}^{m}, s_{1}^{m}, s_{1}^{f}, q_{1}^{f}} x_{1}^{m} \frac{p_{2}\left(s_{1}^{m}, s_{1}^{f}\right)}{1+r}-C_{m}\left(q_{1}^{m}\right)+\frac{\pi_{2}^{m}\left(s_{1}^{m}, s_{1}^{f}\right)}{1+r}
$$

subject to $(24),(25)$ and $p_{2}\left(s_{1}^{m}, s_{1}^{f}\right) /(1+r)=C_{f}^{\prime}\left(q_{1}^{f}\right)$. Letting $\lambda, \mu$ and $\xi$ be, respectively, the Lagrangian multipliers associated to these three constraints, the first order conditions 
are given by

$$
\begin{gathered}
{\left[q_{1}^{m}\right]:-C_{m}^{\prime}\left(q_{1}^{m}\right)-\lambda=0} \\
{\left[x_{1}^{m}\right]: \frac{p_{2}}{1+r}+\lambda-\mu=0} \\
{\left[s_{1}^{m}\right]: x_{1}^{m} \frac{\partial p_{2}}{\partial s_{1}^{m}} \frac{1}{1+r}+\frac{\partial \pi_{2}^{m}}{\partial s_{1}^{m}} \frac{1}{1+r}+\lambda+\xi \frac{\partial p_{2}}{\partial s_{1}^{m}} \frac{1}{1+r}=0} \\
{\left[s_{1}^{f}\right]: x_{1}^{m} \frac{\partial p_{2}}{\partial s_{1}^{f}} \frac{1}{1+r}+\frac{\partial \pi_{2}^{m}}{\partial s_{1}^{f}} \frac{1}{1+r}+\mu+\xi \frac{\partial p_{2}}{\partial s_{1}^{f}} \frac{1}{1+r}=0} \\
{\left[q_{1}^{f}\right]:-\mu-\xi C_{f}^{\prime \prime}\left(q_{1}^{f}\right)=0}
\end{gathered}
$$

To obtain expressions for $\partial \pi_{2}^{m} / \partial s_{1}^{m}$ and $\partial \pi_{2}^{m} / \partial s_{1}^{f}$, let first rewrite (21) as

$$
\pi_{2}^{m}\left(s_{1}^{m}, s_{1}^{f}\right)=x_{2}^{m}\left(s_{1}^{m}, s_{1}^{f}\right) \cdot C_{f}^{\prime}\left(q_{2}^{f}\right)-C_{m}\left(q_{2}^{m}\left(s_{1}^{m}, s_{1}^{f}\right)\right)+\frac{\pi_{3}^{m}\left(s_{2}^{m}\right)}{1+r}
$$

where

$$
\begin{gathered}
q_{2}^{f}=-x_{2}^{m}\left(s_{1}^{m}, s_{1}^{f}\right)-s_{1}^{f}-a^{f}+u^{f} \\
s_{2}^{m}=s_{1}^{m}+q_{2}^{m}\left(s_{1}^{m}, s_{1}^{f}\right)-x_{2}^{m}\left(s_{1}^{m}, s_{1}^{f}\right)+a^{m}-u^{m}
\end{gathered}
$$

Recall that $q_{2}^{m}\left(s_{1}^{m}, s_{1}^{f}\right)$ and $x_{2}^{m}\left(s_{1}^{m}, s_{1}^{f}\right)$ are the solution to (14) for any given $s_{1}^{m}$ and $s_{1}^{f}$. Applying the envelop theorem to (45) yields

$$
\begin{gathered}
\frac{\partial \pi_{2}^{m}\left(s_{1}^{m}, s_{1}^{f}\right)}{\partial s_{1}^{m}}=\frac{d \pi_{3}^{m}\left(s_{2}^{m}\right)}{d s_{2}^{m}} \frac{\partial s_{2}^{m}}{\partial s_{1}^{m}} \frac{1}{1+r} \\
\frac{\partial \pi_{2}^{m}\left(s_{1}^{m}, s_{1}^{f}\right)}{\partial s_{1}^{f}}=x_{2}^{m} \cdot C_{f}^{\prime \prime}\left(q_{2}^{f}\right) \cdot(-1)=-x_{2}^{m} C_{f}^{\prime \prime}\left(q_{2}^{f}\right)
\end{gathered}
$$

But we know from (47) that $\partial s_{2}^{m} / \partial s_{1}^{m}=1$ and from (38) and (19) that $d \pi_{3}^{m}\left(s_{2}^{m}\right) / d s_{2}^{m}=$ $C_{m}^{\prime}\left(q_{3}^{m}\right)=C_{m}^{\prime}\left(q_{2}^{m}\right) \cdot(1+r)$; hence, $\partial \pi_{2}^{m} / \partial s_{1}^{m}=C_{m}^{\prime}\left(q_{2}^{m}\right)$ and $\partial \pi_{2}^{m} / \partial s_{1}^{f}=-x_{2}^{m} C_{f}^{\prime \prime}\left(q_{2}^{f}\right)$.

Replacing the above values of $\partial \pi_{2}^{m} / \partial s_{1}^{m}$ and $\partial \pi_{2}^{m} / \partial s_{1}^{f}$ into (42) and (43) and rearranging leads to

$$
\begin{aligned}
& \left(x_{1}^{m}+\xi\right) \cdot \frac{\partial p_{2}}{\partial s_{1}^{m}} \frac{1}{1+r}=-\lambda-\frac{C_{m}^{\prime}\left(q_{2}^{m}\right)}{1+r} \\
& \left(x_{1}^{m}+\xi\right) \frac{\partial p_{2}}{\partial s_{1}^{f}} \frac{1}{1+r}=-\mu+x_{2}^{m} C_{f}^{\prime \prime}\left(q_{2}^{f}\right)
\end{aligned}
$$


Furthermore, from (40a) and (41) we can express $\lambda$ and $\mu$ as functions of the control variables and from (19) and (20) we know that $p_{2}-x_{2}^{m} \cdot C_{f}^{\prime \prime}\left(q_{2}^{f}\right)=C_{m}^{\prime}\left(q_{2}^{m}\right)$. Replacing these expressions into (48) and (49) yields

$$
\begin{gathered}
\left(x_{1}^{m}+\xi\right) \cdot \frac{\partial p_{2}}{\partial s_{1}^{m}} \frac{1}{1+r}=C_{m}^{\prime}\left(q_{1}^{m}\right)-\frac{C_{m}^{\prime}\left(q_{2}^{m}\right)}{1+r} \\
\left(x_{1}^{m}+\xi\right) \frac{\partial p_{2}}{\partial s_{1}^{f}} \frac{1}{1+r}=C_{m}^{\prime}\left(q_{1}^{m}\right)-\frac{C_{m}^{\prime}\left(q_{2}^{m}\right)}{1+r}
\end{gathered}
$$

Since an increase in stock holdings necessarily leads to more a competitive outcome, we must have that both $\partial p_{2} / \partial s_{1}^{m}$ and $\partial p_{2} / s_{1}^{f}$ are strictly negative. Similarly, since a transfer of a marginal fraction of stock from competitive hands (i.e., fringe) to an strategic player (i.e., large firm) necessarily leads to a less competitive outcome (unless firms are following competitive pricing), we must also have $\partial p_{2} / \partial s_{1}^{f}<\partial p_{2} / \partial s_{1}^{m}$. Without explicitly solving for $\partial p_{2} / \partial s_{1}^{m}$ and $\partial p_{2} / s_{1}^{f}{ }^{13}$ these two observations are sufficient to infer that the only solution of the system (50)-(51) must satisfy $x_{1}^{m}+\xi=0$ and $C_{m}^{\prime}\left(q_{1}^{m}\right)-C_{m}^{\prime}\left(q_{2}^{m}\right) /(1+r)=0$. The latter expression is (28) in the text. To obtain (29), simply replace $\xi=-x_{1}^{m}$ into (44), and that along with $p_{2} /(1+r)=p_{1}$ and $\lambda=-C_{m}^{\prime}\left(q_{1}^{m}\right)$ into (41).

\section{References}

[1] Allaz, B., and J.-L.Vila (1993), Cournot competition, forward markets and efficiency, Journal of Economic Theory 59, 1-16.

[2] Bernard, A., S. Paltsev, J.M. Reilly, M. Vielle and L. Viguier (2003), Russia's role in the Kyoto Protocol, Report No. 98, Joint Program on the Science of Policy and Global Change, MIT.

\footnotetext{
${ }^{13}$ If we consider, as we do in the numerical examples, that $C_{f}\left(q^{f}\right)=\left(q^{f}\right)^{2} / 2$ and $C_{m}\left(q^{m}\right)=\gamma\left(q^{m}\right)^{2} / 2$, where $\gamma$ is some positive parameter, we have that

$$
\frac{\partial p_{2}}{\partial s_{1}^{m}}=-\kappa \text { and } \frac{\partial p_{2}}{\partial s_{1}^{f}}=\frac{-(\kappa+1)}{2}
$$

where $\kappa=\gamma /[(2+r)(2+\gamma)]<1$.
} 
[3] Cronshaw, M. and J.B. Kruse (1996), Regulated firms in pollution permit markets with banking, Journal of Regulatory Economics 9, 179-189.

[4] Ellerman, A.D, P. Joskow, R. Schmalensee, J.-P. Montero, and E.M. Bailey (2000), Markets for Clean Air: The US Acid Rain Program, Cambridge University Press, Cambridge, UK.

[5] Ellerman, A.D., and J.-P. Montero (2005), The efficiency and robustness of allowance banking in the U.S. Acid Rain Program, mimeo, MIT-CEEPR.

[6] Ellerman, A.D., and I. S. Wing (2000), Supplementarity: An Invitation to Monopsony? The Energy Journal 21, 29-59.

[7] Hahn, R. (1984), Market power and transferable property rights, Quarterly Journal of Economics 99, 753-765.

[8] Hagem, C., and H. Westskog (1998), The design of a dynamic tradable quota system under market imperfections, Journal of Environmental Economics and Management, 36, 89-107.

[9] Hotelling, H. (1931), The economics of exhaustible resources, Journal of Political Economy 39, 137-175.

[10] Holmström Bengt, and Barry Nalebuff, To the Raider Goes the Surplus? A Reexamination of the Free-Rider Problem, Journal of Economics and Management Strategy 1, 37-62 (1992).

[11] Grossman, Sanford J., and Oliver D. Hart (1980), Takeover Bids, the Free-Rider Problem, and the Theory of the Corporation, Bell Journal of Economics 11, 42-64 .

[12] Joskow, P., R. Schmalensee, E. Bailey (1998), The Market for Sulfur Dioxide Emissions, American Economic Review, 88, 669-85.

[13] Lewis, T. and R.Schmalensee (1980), On oligopolistic markets for nonrenewable resources, Quarterly Journal of Economics 95, 475-491. 
[14] Liski M., and J.-P. Montero (2004), A Note on Market Power in an Emission Permits Market with Banking, WP-2004-05, MIT-CEEPR.

[15] Liski M., and J.-P. Montero (2004), Forward Trading and Collusion in Oligopoly, WP-2004-012, MIT-CEEPR.

[16] Maeda, A. (2003), The emergence of market power in emission rights markets: The role of the initial permit distribution, Journal of Regulatory Economics 24, 293-314.

[17] Newbery, D.M. (1981), Oil prices, cartels and the problem of dynamic inconsistency, Economic Journal 91, 617-646.

[18] Rubin, J.D. (1996), A model of intertemporal emission trading, banking, and borrowing, Journal of Environmental Economics and Management 31, 269-286.

[19] Salant, S.W. (1976), Exhaustible resources and industrial structure: A NashCournot approach to the world oil market, Journal of Political Economy 84, 10791093.

[20] Schennach, S.M. (2000), The economics of pollution permit banking in the context of Title IV of the 1990 Clean Air Act Amendments, Journal of Environmental Economics and Management 40, 189-210. 